\title{
Functions of innovation systems: A new approach for analysing technological change
}

\author{
M.P. Hekkert ${ }^{\text {a,* }}$, R.A.A. Suurs ${ }^{\text {a }}$, S.O. Negro ${ }^{\text {a }}$, S. Kuhlmann ${ }^{\text {a,b }}$, R.E.H.M. Smits ${ }^{\text {a }}$ \\ a Utrecht University, Copernicus Institute for Sustainable Development and Innovation, Department of Innovation Studies, \\ Heidelberglaan 2, 3584 CS Utrecht, The Netherlands \\ ${ }^{\mathrm{b}}$ Fraunhofer Institute for Systems and Innovation Research ISI, Breslauer Strasse 48, 76139 Karlsruhe, Germany
}

Received 18 October 2005; received in revised form 2 March 2006; accepted 2 March 2006

\begin{abstract}
The central idea of this paper is that innovation systems are a very important determinant of technological change. We describe that the emergence of a new innovation system and changes in existing innovation systems co-evolve with the process of technological change. Therefore, it is necessary to create more insight in the dynamics of innovation systems. Traditional methods of innovation system analysis that mainly focus on the structure of innovation systems have proven to be insufficient. Therefore, we propose a framework that focuses on a number of processes that are highly important for well performing innovation systems. These processes are labeled as 'functions of innovation systems'. After explaining this framework and embedding it in existing literature, we propose a method for systematically mapping those processes taking place in innovation systems and resulting in technological change. This method can be characterized as a process analysis or history event analysis. Clarifying examples are taken from the empirical field of Sustainable Technology Development.

(C) 2006 Elsevier Inc. All rights reserved.
\end{abstract}

Keywords: Transition management; Innovation system dynamics

\section{Introduction}

There is a strong need to influence both speed and direction of innovation and technological change. In this paper, when using the concept of technological change, we do not refer to technology

\footnotetext{
* Corresponding author. Tel.: +31 30253 6112; fax: +31 302532746 .

E-mail address: m.hekkert@geo.uu.nl (M.P. Hekkert).
} 
development in the narrow sense, but to the development of technology in interaction with the system in which the technology is embedded. We call this joined and interactive process the innovation process. An innovation can be defined as the successful combination of hardware, software, and orgware, where orgware refers to the various components of the innovation system [1]. Increasing the speed of innovation is important, since innovation is a key determinant for long term economic growth and development. Increasing the innovation speed at a national level is a highly complicated process, yet influencing the innovation direction is even harder.

The necessity to shape innovation processes can be demonstrated by the fact that apart from the advantage of creating economic growth and societal benefits, current use of technologies often have severe negative side effects. Quite often these negative side effects are related to the impact of technology on the natural environment. The relation between technology and the environment is complex and paradoxical [2]. On the one hand, technologies use resources and impose environmental stress. On the other hand, technologies can also lead to a more efficient use of resources, less stress on the environment and even cleaning of the environment.

The latter is often referred to as Sustainable Technology Development [3]. Technology development is not an autonomous process and, therefore, management of technological change is necessary. The design and implementation of these management processes is a key issue in many national environmental and innovation policy programs.

In order to make technological change sustainable, technical change alone is not sufficient. Changes in the social dimension-such as user practices, regulation, and industrial networks-are inevitable [4]. The recognition of this system level of change has led to a rapid diffusion of concepts such as technological transition [4] and industrial or socio-technical transformation [5].

Both science and policy community recognize ever increasingly that technological change and its resulting innovations are best understood as the outcome of innovation systems [6]. The concept of 'innovation systems' is a heuristic attempt, developed to analyse all societal subsystems, actors, and institutions contributing in one way or the other, directly or indirectly, intentionally or not, to the emergence or production of innovation. If we knew what kind of activities foster or hamper innovationthus, how innovation systems 'function'-we would be able to intentionally shape innovation processes.

The use of the innovation system framework to understand technological change, has two shortcomings. First, even though this framework is based on theories such as interactive learning (e.g., [7]) and evolutionary economics (e.g., [8]), most analyses of innovation systems are quasi-static in character. There is a focus on comparing the social structure of different innovation systems (actors, their relations, and institutions) and, thereby, explaining the differences in performance. Less emphasis is put on the analysis of the dynamics of innovation systems. Second, the explanatory power of the framework lies mainly in the part of institutions (macro level), and less on the actions of the entrepreneur (micro level), even though an often quoted rationale behind the concept of innovation systems is that 'innovation is both an individual and a collective act' [9]. One might say that the innovation system framework suffers from institutional determinism; this is problematic, since the individual perspectiveespecially that of the entrepreneur(s)-is fundamental in practically all innovation literature. The entrepreneur is even likely to (now and then) overthrow and change (parts of the) structures around him, thus forcing the process of technical change into new directions.

Since technological change is a dynamic process, which requires a transformation of the innovation system in which changes take place, a dynamic innovation system approach is needed to understand and better be able to guide its direction. The basic notion of this paper is that by applying the innovation 
system framework, much can be learned from innovation studies that take the firm, or the entrepreneurial project, as a starting point. These studies pay considerably more attention to the dynamics of innovation processes. In this paper we aim to incorporate insights from the work of Van de Ven and colleagues on the innovation journey to strengthen empirical work on the dynamics of innovation [10].

The central idea of this paper is that the analysis of technological change should focus on systematically mapping the activities that take place in innovation systems resulting in technological change. Since these activities have the function to contribute to the goal of the innovation system, which is the generation and diffusion of innovations, the activities are often called functions of innovation systems [11]. The aim of this article is to explain this approach and discuss a number of methodological issues that need to be dealt with when applying this approach. Clarifying examples are taken from the empirical field of Sustainable Technology Development.

\section{Technological change and innovation systems}

Over the last decades, institutional theories combined with evolutionary theories have led to the Innovation System (IS) approach [12]. The central idea behind the IS approach is that innovation and diffusion of technology is both an individual and a collective act [9]. The IS approach encompasses individual firm dynamics as well as particular technology characteristics and adoption mechanisms. Determinants of technological change are not only to be found within the individual firm, but also within the IS. An IS can be defined as all institutions and economic structures that affect both rate and direction of technological change in society [13]. Or as Freeman (1987) puts it: an IS is "...The network of institutions in the public and private sectors whose activities and interactions initiate, import, modify, and diffuse new technologies" [14].

Applying the systemic aspect of the systems of innovation approach in order to understand technological change has large implications. The systemic character of technological change explains why technological change is often a very slow process and why it is so difficult to influence. After all, the rate and direction of technological change is not so much determined by the simple competition between different technologies, but predominantly by the competition between various existing innovation systems, both fully developed and emerging ones. The inertia of 'technology-innovation system' combinations is quite large, which can lead to a lock-in that results in relatively rigid technological trajectories. Kemp puts it as follows: "One of the key reasons why technological progress often proceeds along certain trajectories is that the prevailing technology and its design has already benefited from all kinds of evolutionary improvements, in terms of costs and performance characteristics, from a better understanding at the user side, and from the adaptation of the socio-economic environment in terms of accumulated knowledge, capital outlays, infrastructure, available skills, production routines, social norms, regulations and lifestyles" [15]. Therefore, understanding technical change implies creating insight in the relations between incumbent technology and the incumbent (innovation) system in relation to the emerging technology and the emerging innovation system.

This is also the central idea of the Multi Level Model [16]. In this model the innovation system related to the incumbent technology is labelled as 'regime', while the 'incubation rooms' for emerging technologies (the novelties) are labelled as 'niches'. The central question in this model is: under which circumstances becomes a niche so successful that it becomes part of the existing regime? In our terminology: what are the conditions that foster the growth of an emerging innovation system in such a 
way that it becomes so large and entrenched in society, that it is able to compete with and even become part of existing (innovation) systems?

Note that this question requires a specific definition of innovation systems: one that is strongly related to change. We therefore adopt the concept of technological system $[17,18]$. Here, the principle starting point is not a geographical area (as in National Systems of Innovation, NSI) or an industrial sector (Sectoral Innovation System, SIS), but a technology. It is defined by Carlsson and Stankiewicz [17] as:

"a network of agents interacting in the economic/industrial area under a particular institutional infrastructure (...) and involved in the generation, diffusion, and utilization of technology."

In his recent volume on The Globalizing Learning Economy, Lundvall also suggests that a promising direction is to study 'technological systems': "...it is useful to think in terms of 'technological systems' as a special version of innovation systems. A technological system is a combination of interrelated sectors and firms, a set of institutions and regulations characterizing the rules of behavior and the knowledge infrastructure connected to it. Most innovation policies [...] are well suited when it comes to supporting existing technological systems, but much less when it comes to stimulating the creation of new ones." [19].

Both [17] and [19] use the term 'technological systems', but this term usually refers to the notion of 'Large Technological Systems' (LTS), introduced by Hughes [20]. The LTS, as conceptualized, consists of physical artifacts, organizations, and legislative artifacts (institutions) [20]. Take for example the energy system: within the LTS framework, wind mills, gas turbines, transformers, and the electricity grid are all part of the system, whereas in the case of [17,19], these artifacts are excluded. To avoid confusion we will refer to the technological systems in Hughes' sense as LTS; we will label the technological systems of [17,19] as Technology Specific Innovation Systems (TSIS).

A technology, or the knowledge it embodies, is hardly ever embedded in just the institutional infrastructure of a single nation or region, since-especially in modern society-the relevant knowledge base for most technologies originates from various geographical areas all over the world. We find a similar argument for the relevance of a strictly sectoral delineation. Thus, by taking a specific technology as a starting point, the technological system approach cuts through both the geographical and the sectoral dimensions. Take for example the development and diffusion of solar cells: this depends on technological progress made in research institutes and universities all over the world. Thus, the solar cell innovation system overlaps with those parts of national innovation systems that concentrate on solar cell research. In turn, global diffusion strongly depends on different national policy regimes that stimulate the adoption of solar cells by means of investment subsidies or feed-in laws. Again, the solar cell innovation system overlaps with various national innovation systems in terms of stimulating institutions for solar cell diffusion. Furthermore, the production conditions for solar cells strongly depend on the microelectronics sector due to competition over silicon wavers. Silicon wavers are produced for the microelectronics sector, but the surplus of wavers is sold to solar cell manufacturers. High growth rates in the microelectronics sector lead to silicon shortages and higher prices of solar cells. Furthermore, the application of solar cells strongly depends on the housing sector, including architecture. Solar cell friendly architecture can greatly influence the potential for solar cells in the building environment and the energy output of these cells. Thus, the technological progress, price, and diffusion of one technology is influenced by the various national innovation systems and sectoral innovation 


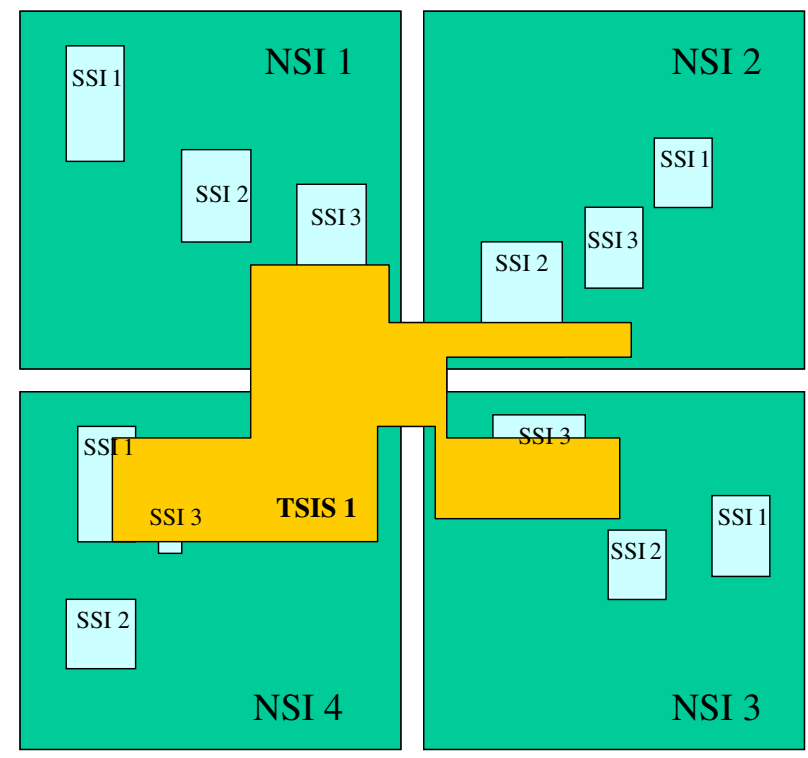

Fig. 1. Boundary relations between National, Sectoral, and Technology Specific Innovation Systems.

systems. This is illustrated in Fig. 1, which schematically shows how the Technology Specific Innovation System relates to the geographical and sectoral dimensions of respectively the NSI and the SIS approach. It shows that the Technology Specific Innovation System overlaps with parts of various national innovation systems and with various sectoral innovation systems which, in turn, are embedded in national systems of innovations.

\section{Dynamics of technology specific innovation systems}

We have argued that, in order to understand technological change, one needs insight in innovation system dynamics. New laws, entry of new actors, and other events change the character of an innovation system over time. However, when innovation systems are studied at a national level, the dynamics are difficult to map. After all, the complexity of the NSI is quite extreme, due to the vast amount of actors, network relations, and institutions. This is why many authors who study and compare NSIs, focus on the current structure of the NSIs. Typical indicators to assess the structure of an NSI are R\&D efforts, patents and patent applications, qualities of educational systems, university-industry collaborations, and availability of venture capital. Thus, most empirical studies on innovation systems do not focus on mapping the dynamics.

In Technology Specific Innovation Systems, the number of actors, networks, and relevant institutions is generally much smaller than in NSIs; this reduces the complexity and, therefore, on this aggregation level, a dynamic analysis seems well possible. Jacobsson and Johnson state that the technology specific approach is the most dynamic of all IS approaches. This is demonstrated in empirical studies on the diffusion of renewable energy technologies, see [11,21,22].

In order to understand the determinants of change, insight in the present (static) structure of innovation systems is not sufficient. Ideally, we would like to grasp the dynamics of innovation systems 
in order to reach a better understanding of what really takes place inside these systems. Therefore, we propose to map the activities that take place within the system, since the process of change is the resultant of many interrelated activities.

The following example clarifies why insight in system dynamics and activities is an improvement compared to insights in system structure alone. Both Germany and the Netherlands have specific policies to stimulate renewable energy. However, Germany is considerably more successful in terms of diffusion rates. If we wanted to explain this in terms of innovation system structure, we would for example map all current regulations regarding sustainable energy. Furthermore, we would map which agents are present in the German and Dutch innovation system, producing, implementing, and diffusing sustainable energy technologies. The comparison would show that German sustainable energy producers receive higher prices and are able to negotiate longer-term contracts. This would already explain a large part of the success in Germany. What would a dynamic system analysis add? A dynamic analysis would show how the regulations came in place. It would show how the renewable energy lobby, opposition, and external events influenced the emergence of renewable energy regulation. It would show the co-evolutionary process of regulations adaptation and learning experiences from previous institutional arrangements. Furthermore, it would show the interactive relation between government actions and increasing or decreasing entrepreneurial activities, the availability of resources for innovation projects and the legitimization of renewable energy in society. In short, it would provide insights in the interaction of forces that determine the slow and difficult change of a merely locked-in system towards a new equilibrium. Fundamental insights in how these processes work are of crucial importance when the aim is to stimulate and steer technological change.

The disadvantage of creating insight in innovation system dynamics is that many different activities take place in innovation systems. To map them all simply is not feasible. Therefore it is necessary to only map the relevant activities. Activities in innovation systems are considered relevant when they influence the goal of the innovation system. The goal of an innovation system is to develop, apply, and diffuse new technological knowledge. In literature, the activities that contribute to the goal of innovation systems (both positive and negative), are called 'functions of innovation systems' [23].

\section{Functions in literature}

Traditional literature often uses the term 'function' in relation to particular institutions [24,25] or to the system as a whole [7,17]. However, few articles use the concept of functions to structure empirical work, i.e., to map system dynamics. Before elaborating on the significance of functions within the IS framework, a short historical overview is given.

The most basic function mentioned in many IS studies, is the activity of 'learning' or 'interactive learning'. This activity lies at the core of the IS approach [7]. Edquist and Johnson [25] mention three functions of institutions in innovation systems: institutions reduce uncertainty by providing information, manage conflicts and cooperation, and provide incentives for innovation. McKelvey [26] discerns three different functions of innovation systems as she explicitly defines the IS according to evolutionary theory: (i) retention and transmission of information, (ii) generation of novelty leading to diversity, and (iii) selection among alternatives. The necessary activities within the IS correspond precisely with the main principles of evolutionary economics: variety, selection, and retention. The importance of networking is particularly stressed. 
Galli and Teubal [24] pay specific attention to NSI functions and linkages as they discuss evolution and transition of innovation systems. They state it is important to make a distinction between organizations and functions, since organizations increasingly have multiple roles. They distinguish between hard and soft functions. Hard functions require hard organizations (i.e., performing R\&D), while soft functions may be operated by soft institutions (not performing R\&D as for instance regulatory entities) and involve catalytic and interface roles only [24]. Hard functions are: (i) R\&D activities (public) and (ii) the supply of scientific and technical services to third parties (business sector and public administration). Soft functions include: (i) diffusion of information, knowledge, and technology; (ii) policy making; (iii) design and implementation of institutions concerning patents, laws, standards, etc.; (iv) diffusion of scientific culture, and (v) professional coordination. Even though Galli and Teubal [24] stress the importance of distinguishing between organizations and functions, the functions are a relatively straight extrapolation from the classic modules present within IS (knowledge development infrastructure, demand side, intermediate infrastructure, and supportive infrastructure). Functions at a more abstract level which can be fulfilled by separate parts of the innovation system, such as the functions of McKelvey [26], are not present in their overview.

This type of direct extrapolation from system modules to functions is also done by Liu and White [27], which addresses what they call a fundamental weakness of national innovation system research, namely "the lack of system-level explanatory factors". They focus therefore on the following 5 activities in the systems [27]:

- Research (basic, development, engineering)

- Implementation (manufacturing)

- End-use (customers of the product or process output)

- Linkage (bringing together complementary knowledge)

- Education

Johnson [23] is completely dedicated to the concept of functions. An overview of innovation system literature is given to find out whether or not a shared understanding of which functions ought to be served in innovation systems is present. Based on this literature overview she identifies 8 system functions:

- Supply incentives for companies to engage in innovative work

- Supply resources (capital and competence)

- Guide the direction of search (influence the direction in which actors deploy-resources)

- Recognize the potential for growth (identifying technological possibilities and economic viability)

- Facilitate the exchange of information and knowledge

- Stimulate/create markets

- Reduce social uncertainty (i.e., uncertainty about how others will act and react)

- Counteract the resistance to change that may arise in society when an innovation is introduced (provide legitimacy for the innovation)

This set of functions differs from the previous sets, since these functions are formulated in an active sense. In this case the functions are almost synonymous with a set of policy recommendations. In fact 
this set of functions seems to suggest that the typical modules in innovation systems are present, but that key activities need to be performed before these modules can function well. Note the difference between Liu and White's 'Research' and Galli and Teubal's 'R\&D' on the one hand and the first three functions of Johnson [23] on the other. The latter indicates which system activities need to take place in order to make effective and efficient research possible.

In the empirical work following the work of Johnson [23], the list of 8 functions is reduced to 5 functions [28]:

- Create new knowledge

- Guide the direction of search processes

- Supply resources

- Facilitate the creation of positive external economies (in the form of an exchange of information, knowledge, and visions)

- Facilitate the formation of markets

In these empirical studies, this approach proved to be suitable to describe and begin to explain the transformation of specific transitions in technology specific innovation systems. The construction of this set of functions and its use for empirical studies is in line with the recommendations given by Lundvall et al. [29], who states that making the system of innovation concept more dynamic is a major step in the direction of future research. Furthermore, he advises to focus on all aspects of competence building (not just a narrow focus on science and science-based activities). This is precisely what using this set of functions does.

There are three reasons for adopting the functions approach. First, this perspective makes comparison in terms of performance between innovation systems with different institutional set-ups more feasible. Second, the functions perspective permits a more systematic method of mapping determinants of innovation; this increases the analytical power of the IS approach, especially when doing a longitudinal analysis: "The external dynamics of an innovation may be studied by drawing maps of functional patterns over time. The internal dynamics are created by the interaction of functions, which make it possible for cumulative and circular causation to appear. By studying feedback loops between functions it is, thus, possible to get a picture of the internal dynamics of the system" [30]. Third, the functions perspective has the potential to deliver a clear set of policy targets as well as instruments to meet these targets: "System performance may be evaluated in terms of the 'functionality' of a particular innovation system, i.e., in terms of how well the functions are served within the system. The meaning of 'well served' for capital goods industry development is expected to differ depending on what particular stage of evolution an industry is in" [30-32].

From a policy perspective, Smits and Kuhlman [1] conclude that present-day innovation processes ask for (more attention for) instruments that support the following functions:

- Manage interfaces; cut across subsystem borders and supersede tunnel visions and dead-locks of narrow negotiation arenas; stimulate the debate.

- Build and organize (innovation) systems; facilitate construction ('Neue Kombinationen') and deconstruction ('creative destruction') of (sub)systems; initiate discourse, alignment, consensus. Prevent lock-in; identify and facilitate prime movers, ensure that all relevant actors are involved. All 
these are part of this function. As an illustration for the case of energy systems, we already referred to [33].

- Provide a platform for learning and experimenting; create conditions for various forms of learning such as: learning by doing, learning by using and learning by interacting [7,34].

- Provide an infrastructure for strategic intelligence; identify sources (Technology Assessment, Foresight, Evaluation, Bench Marking); build links between sources; improve accessibility for all relevant actors (Clearing house); stimulate the development of the capacity to produce strategic information tailored to the needs of actors involved [35].

- Stimulate demand articulation, strategy, and vision development.

- Stimulate and facilitate the search for possible applications; develop instruments that support discourse, vision, and strategy development. This last point, as is point 4, is further illustrated by the growing body of knowledge on the role of users in innovation processes [36].

Instruments that function at system level already exist. Examples are non-product standards [37], foresight programs [38], and information campaigns of governments and branch organizations to raise the awareness of the public and enterprises for the opportunities offered by specific technologies. However, recent evaluations of innovation policy instruments in several OECD countries, show that the policy instruments portfolio is still heavily dominated by financial instruments. In their comparative analysis of the innovation policy instrument portfolios of nine countries, Boekholt et al. [39] conclude: "If we look at the current policy mix in the benchmark countries we see that supporting R\&D in individual companies is still the major objective of innovation policies in many countries." It may be clear that systemic instruments are an important addition to the policy instruments portfolio, to better equip this portfolio to stimulate the innovation system functions as discussed in the foregoing.

\section{Proposed set of functions}

Based on the different categories of functions and several empirical studies at Utrecht University $[40,41]$, we propose the following set of functions to be applied when mapping the key activities in innovation systems, and to describe and explain shifts in technology specific innovation systems. ${ }^{1}$

\subsection{Function 1: entrepreneurial activities}

There is no such thing as an innovation system without entrepreneurs. Entrepreneurs are essential for a well functioning innovation system. The role of the entrepreneur is to turn the potential of new knowledge, networks, and markets into concrete actions to generate-and take advantage of-new business opportunities. Entrepreneurs can be either new entrants that have the vision of business opportunities in new markets, or incumbent companies who diversify their business strategy to take advantage of new developments.

\footnotetext{
${ }^{1}$ This list of functions is, to a large extent, harmonized with colleagues from Chalmers University (Sweden) to be used in empirical work both in Utrecht and Chalmers.
} 
The entrepreneurs' risky experiments are necessary to cope with the large uncertainties that follow from new combinations of technological knowledge, applications and markets. ${ }^{2}$ By experimenting, more knowledge can be collected about the functioning of the technology under different circumstances. Moreover, reactions of consumers, government, competitors, and suppliers can be evaluated. By experimenting, many forms of learning take place.

The presence of active entrepreneurs is a first and prime indication of the performance of an innovation system. When entrepreneurial activity lags behind, causes may be found in the other six functions. We expect that the odds of a firm successfully developing an innovation, primarily depend on how the innovation system is developed in terms of functions 2 to 7 ; a well functioning system will probably lead to a climate in which entrepreneurial activities blossom. Van de Ven stresses that these functions should not be seen as external factors that cannot be influenced by the entrepreneur. In fact, since a well functioning innovation system is critical to the success of the entrepreneur, he will have to decide on how much effort he will dedicated to in-firm processes and how much to influencing the system around him. Usually, one entrepreneur cannot fulfill all functions simultaneously by himself. Therefore, Van de Ven formulates three questions that-from the viewpoint of the individual firm-need to be answered: 1) which functions will the entrepreneur perform?, 2) which organizations should the firm link to, in order to perform other functions?, and 3) which organizations will the firm compete with on certain functions? [43].

An illustration can be taken from the case of biofuels in the Netherlands. Since the Dutch government has been reluctant to give tax exemptions for biofuels, several entrepreneurs collectively lobby for this tax exemption, all stressing the benefit of biofuels for the environment. At the same time these entrepreneurs compete for collective R\&D resources and, in this process, they emphasize the benefits of their specific technology over other technologies [41]. From Suurs and Hekkert it becomes clear that incumbent entrepreneurs who aim to diversify their business strategy, are much more active in fulfilling system functions than new start ups [41].

This function can be analysed by mapping the number of new entrants, the number of diversification activities of incumbent actors, and the number of experiments with the new technology.

\subsection{Function 2: knowledge development}

As mentioned above, mechanisms of learning are at the heart of any innovation process. For instance, according to Lundvall: "the most fundamental resource in the modern economy is knowledge and, accordingly, the most important process is learning" [7]. Therefore, R\&D and knowledge development are prerequisites within the innovation system. This function encompasses 'learning by searching' and 'learning by doing'.

Three typical indicators to map this function over time are: 1) R\&D projects, 2) patents, and 3) investments in R\&D. While these indicators map the effort put into knowledge development, one might also map the increase in technological performance by means of so-called learning curves [44].

\footnotetext{
${ }^{2}$ This uncertainty is a fundamental feature of technological and industrial development. In [42] a framework is presented regarding uncertainties in technological transitions. They distinguish between technological, resource, competitive, supplier, consumer, and political uncertainty.
} 


\subsection{Function 3: knowledge diffusion through networks}

According to [17] the essential function of networks is the exchange of information. This is important in a strict R\&D setting, but especially in a heterogeneous context where R\&D meets government, competitors, and market. Here policy decisions (standards, long term targets) should be consistent with the latest technological insights and, at the same time, R\&D agendas should be affected by changing norms and values. This way, network activity can be regarded as a precondition to 'learning by interacting'. When user producer networks are concerned, it can also be regarded as 'learning by using'.

This function can be analysed by mapping the number of workshops and conferences devoted to a specific technology topic, and by mapping the network size and intensity over time.

\subsection{Function 4: guidance of the search}

Since resources are almost always limited, it is important that, when various technological options exist, specific foci are chosen for further investments. Without this selection there will be insufficient resources left for the individual options. This function can be fulfilled by a variety of system components such as the industry, the government, and/or the market. When knowledge creation (function 2) is regarded as the creation of technological variety, this function represents the process of selection.

Also, from a societal stance, guidance of the search is an important activity. Where functions 2 and 3 referred to mechanisms of learning, without discussing the direction of the learning process, guidance of the search indicates that technological change is not autonomous. Changing preferences in society, if strong and visible, can influence R\&D priority setting and thus the direction of technological change.

As a function, guidance of the search refers to those activities within the innovation system that can positively affect the visibility and clarity of specific wants among technology users.

An example in the field of renewable energy is the long-term goals that are set by different governments to reach a certain share of renewable energy in the future. The Netherlands for example formulated the ambition to reach a share of $10 \%$ renewable energy in 2020 . This ambition grants a certain degree of legitimacy to the development of sustainable energy technologies and stimulates the allocation of resources for this development. Another example is formed by the ambitious goals set by the Californian Air Resources Board in 1990, to oblige the major car manufacturers to bring zero emission vehicles to the market in 2003. Frenken et al. showed that this long term policy goal led to an increase in R\&D activities to develop low emission vehicles [45].

Note that guidance of the search is not solely a matter of market or government influence; it is often an interactive and cumulative process of exchanging ideas between technology producers, technology users, and many other actors, in which the technology itself is not a constant but a variable. Expectations are an important, though elusive, phenomenon in this (see the work of [46] and [47]). Often actors (whether R\&D focused or policy minded) are initially driven by little more than a hunch. Vague ideas are often tried out in experiments (function 1), their success (and failure) can be communicated to other actors (function 3), thereby reducing the (perceived) degree of uncertainty. This in turn triggers expectations, which are communicated throughout the system (function 4). Occasionally, under the influence of 'success stories', expectations on a specific topic converge and generate a momentum for change in a specific direction. 
A classic example that shows the role of expectations in technology development is the case of hydrogen energy. The promise of this fuel is that it is ultra clean (it only leads to water vapor when converted into useful energy) and that it can be produced from a wide variety of sources (electrolysis of water, gasification of biomass, coal, and natural gas). The successful development and implementation of hydrogen technologies is a major challenge. Major cost reductions are necessary, technological breakthroughs are required, and a complete alteration of our energy infrastructure is necessary. Although policy makers and engineers are aware of these challenges, the high expectations regarding this energy carrier are a major incentive to finance and conduct research to overcome these challenges. The type of wording used by scientists and policy makers is often a good indication for these expectations. President Bush used the term 'freedom fuel' when he announced his decision to grant large funds to the development of hydrogen fuelled fuel cell vehicles.

This function can be analysed by mapping specific targets set by governments or industries regarding the use of a specific technology and by mapping the number of articles in professional journals that raise expectations about new technological developments. By counting the number of articles that are positive or negative regarding the new technology development, the state of the debate can be assessed. A strong discussion about the potential benefits of new technology is likely to hamper future developments, while a strong emphasis on the positive aspects is likely to stimulate technology development.

\subsection{Function 5: market formation}

New technology often has difficulty to compete with embedded technologies. Rosenberg puts it like this: "Most inventions are relatively crude and inefficient at the date when they are first recognized as constituting a new innovation. They are, of necessity, badly adapted to many of the ultimate uses to which they will eventually be put; therefore, they may offer only very small advantages, or perhaps none at all, over previously existing techniques. Diffusion under these circumstances will necessarily be slow" [48]. Because of this, it is important to create protected space for new technologies. One possibility is the formation of temporary niche markets [49] for specific applications of a technology. Within such an environment actors can learn about the new technology (function 2 and 3) and expectation can be developed (function 4). Another possibility is to create a (temporary) competitive advantage by favorable tax regimes (e.g., the Dutch experience with reducing taxes for renewable energy) or minimal consumption quotes (e.g., the German feed-in law for renewable energy).

This function can be analysed by mapping the number of niche markets that have been introduced, specific tax regimes for new technologies, and new environmental standards that improve the chances for new environmental technologies.

A clear example of the role of market formation on technology development can be found in the comparison of Germany and the Netherlands regarding the production and use of biofuels. In Germany fuels based on renewable resources enjoy a tax exemption. This has proved a major stimulus for all kind of initiatives to produce biofuels and to bring them to the market, since the costs of biofuels for consumers are equal to that of fossil fuels. The result is that German cars are adapted to make the use of biofuels possible and that biofuels are available at many gas stations in Germany. In the Netherlands, no structural tax exemption was granted. This has blocked initiatives regarding this technology, and biofuels are still not available for the general public [41]. 


\subsection{Function 6: resources mobilization}

Resources, both financial and human capital, are necessary as a basic input to all activities within the innovation system. For a specific technology, the allocation of sufficient resources is necessary to make knowledge production possible. In this sense, this function can be regarded as an important input to function 2.

Examples of this activity are funds made available for long term R\&D programs set up by industry or government to develop specific technological knowledge, and funds made available to allow testing of new technologies in niche experiments (function 1).

This function is difficult to map by means of specific indicators over time. In this case the best suited method to create insight in the fulfillment of this function is to detect, by means of interviews, whether or not inner core actors perceive access to sufficient resources as problematic.

\subsection{Function 7: creation of legitimacy/counteract resistance to change}

In order to develop well, a new technology has to become part of an incumbent regime, or it even has to overthrow it. Parties with vested interests will often oppose to this force of 'creative destruction'. In that case, advocacy coalitions can function as a catalyst; they put a new technology on the agenda (function 4), lobby for resources (function 6) and favorable tax regimes (function 5), and by doing so create legitimacy for a new technological trajectory [50]. If successful, advocacy coalitions will grow in size and influence; they may become powerful enough to brisk up the spirit of creative destruction. The scale and successes of these coalitions directly depend on the available resources (function 6) and the future expectations (function 4) associated with the new technology.

This function can be analysed by mapping the rise and growth of interest groups and their lobby actions.

To illustrate this function, we return to the example of biofuels in Germany. The success was not only based on the structural tax exemption but also on a fierce lobby for this new technology. The centre of the lobby was the agricultural sector. Farmers were able to get EU-subsidies within the so-called 'set aside program': they acquired subsidies when allocating land to the production of non-food crops. By producing canola they were able to enjoy the benefits of this subsidy and make money by selling biodiesel based on canola oil. This benefit led to the foundation of the Union For the promotion of Oil and Protein plants (UFOP). The UFOP quickly became a platform for constructive cooperation between plant breeders, farmers, agricultural traders, oil mills, biodiesel producers, and representatives of government and the science community. They initiated an early market (function 5) for biodiesel by means of a comprehensive tractor fleet, and persuaded taxi companies to adopt biodiesel as fuel. In turn the taxi companies demanded guaranties from the automotive sector, which resulted in the statement by Volkswagen in 1995 that all new models were warranted to run on biodiesel. The rise of biofuels seemed to be irreversible from that point on, resulting in 1300 commercial gas stations in 2003 [51].

\section{Functions, interactions and momentum}

Functions influence each other. Fulfillment of a certain function quite likely has its effects on the fulfillment of other functions. For example, we have seen in the hydrogen case that a clear legitimacy 
(function 4: guidance of the search) has positive effects on knowledge creation. At the same time, a certain amount of knowledge creation is necessary to create expectations about the new technology, which may eventually lead to the building up of legitimacy. Therefore, we expect a non-linear model with multiple interactions between functions, which will either positively or negatively affect the overall performance of the system. The fact that functions positively interact and influence each other can be considered a necessary condition for structural change and, thus, for systemic innovation. Jacobsson and Johnson have described the mechanisms of change processes of innovation systems [33]. According to them the function fulfillment could lead to virtuous cycles of processes of change (or positive feedback loops) that strengthen each other and lead to the building up of momentum to create a process of creative destruction within the incumbent system. Therefore, empirical research should focus on creating insight in how the process of momentum building takes place. This should lead to important insights in how to influence the innovation direction in nations and sectors.

Since we have defined 7 functions, many possible interactions are possible. However, the number of possible starting points is much smaller. Our empirical work shows that developments often start with a limited number of functions that pull other system functions. Fig. 2 depicts three of such initial patterns, which we label as motors of change.

A common trigger for virtuous cycles in the field of sustainable technologies is function 4: guidance of the search. In this case societal problems are identified and government goals are set to limit environmental damage. These goals lead to new resources which, in turn, lead to knowledge development and increasing expectations about technological options (motor C in Fig. 2) [52].

Another possible start for virtuous circles are entrepreneurs who lobby for better economic conditions to make further technology development possible (function 7: counteract resistance to change). They either lobby for more resources to perform R\&D which may lead to higher expectations (motor B, Fig. 2), or they lobby for market formation since very often a level playing field is not present (motor A, Fig. 2). When markets are created, a boost in entrepreneurial activities [F1] is often visible leading to more knowledge formation [F2], more experimentation [F1], and increased lobby [F7] for even better conditions and high expectations that guide further research [F4].

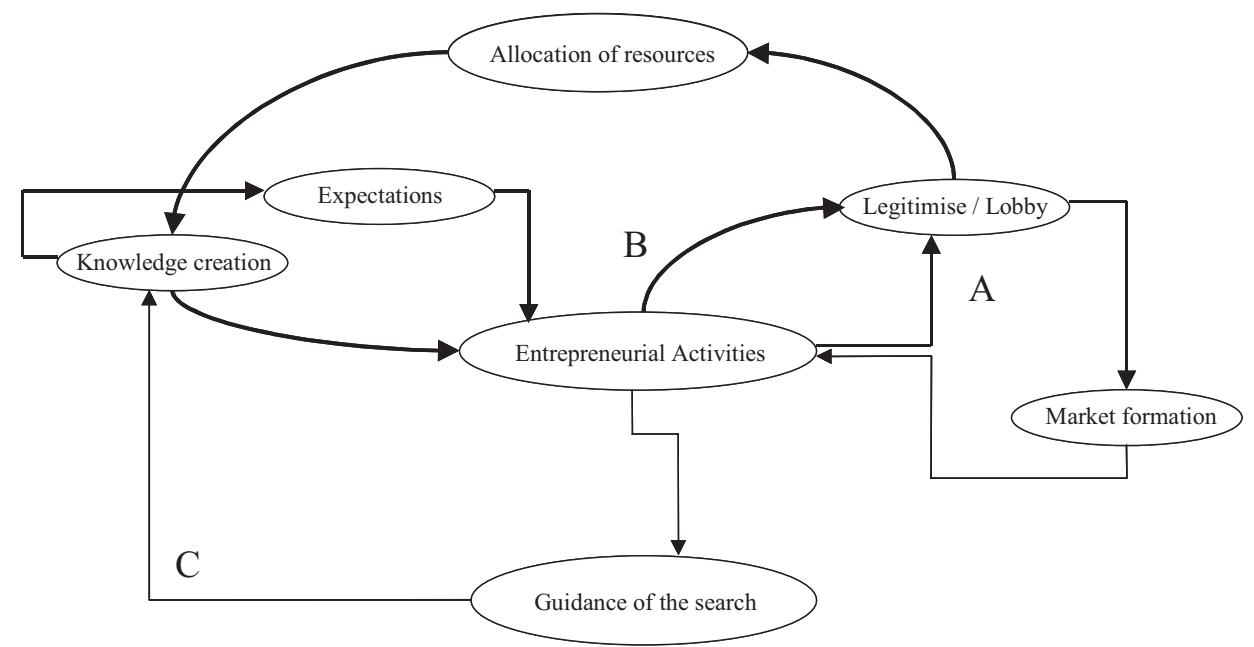

Fig. 2. Three typical motors of change. 
The latter example took place in the Netherlands when the Dutch government decided to grant tax exemptions for a number of local initiatives for the application of biofuels [41].

Vicious cycles are also possible. In this case negative function fulfillment leads to reduced activities related to other functions and thereby slowing down or stopping progress. An example of a vicious cycle is the case of biomass gasification in the Netherlands. The expectations of this technology were very high, until several demonstration projects showed poor results. This led to a collective disappointment in the technology, which in turn negatively influenced new projects, the availability of resources, and knowledge development. It took years before the biomass gasification innovation system was back on track [53].

\section{Process analysis as mapping method}

The whole purpose of using the concept of functions of innovation systems is to understand processes of technological change and innovation. We have argued that acceleration in system change may occur when functions interact and lead to virtuous cycles. System change only takes place when certain thresholds of function fulfillment are reached. Thus, we need a research approach that takes the order and sequence of all relevant processes into account. Therefore, the dominant research strategy in the social sciences, the variance approach, is inadequate for analyzing how function fulfillment leads to system change. This approach is well suited for explaining continuous change driven by simple unidirectional deterministic causation, yet it ignores the order of events. Moreover, the qualitative aspects of the various processes and the richness of the information they generate are often neglected when using statistical approaches.

A more fruitful research approach is the so-called process approach or sequence analysis [54-56]. The process approach conceptualizes development and change processes as sequences of events. It explains outcomes as the result of the order of events. It encompasses continuous and discontinuous causation, critical incidents, contextual effects and effects of formative patterns [54].

Where the variance approach leads to insights as for instance: the presence of function $X$ explains partly the development of the new technology, the process approach presents a story line of how function $X$ influences technology development and at the same time all the other functions. Thus, the process approach creates much more insight in the underlying mechanisms that determine technological change through time.

How is an approach like this applied? The basis of the process approach is the 'event'. Events are what the central subjects do or what happens to them. In studies of Van de Ven and colleagues carried out in the framework of the Minnesota project, events around a specific innovation project were mapped [10]. Due to such a focus on the micro level of innovation, quite detailed information can be gathered by means of observing organizational meetings, studying minutes of meetings, organizational reports, etc. This type of study can even been done real time. In our case we aim to map the events that take place within the technology specific innovation system under investigation. This implies a much broader research focus. The data collection in this case is not so much focused on following all the individual agents or innovation projects in the system, but on events that are reported at the system level. Suitable sources to collect information on the events that took place are newspaper archives and professional journals. Based on a data search, a historical database is constructed in which all relevant events related to a specific technological trajectory are mapped. These events can be workshops on the technology, the 
start up of R\&D projects, expressions of expectations about the technology in the press, announcements of resources that are made available, etc.

All the events that are mapped are then allocated to the seven functions by means of an allocation scheme. This procedure allows the researcher to check the false validity of the seven functions. When many events are difficult to allocate to either one of the seven functions, this is a clear indication that the list of functions is not complete or all together senseless. On the other hand, when only a very small number of events relate to a specific function, this function might not be relevant to understand technological change. First results based on empirical studies on the dynamics of the innovation systems around biomass digestion, biomass gasification, and biofuels in the Netherlands showed that the set of functions corresponds well with empirical data $[40,41,53]$.

Events can either positively or negatively contribute to the functioning of the innovation system. Therefore, all events are categorized as either positive or negative. For example, events that are categorized as knowledge development are rated positive when research projects start, and negative when they are terminated. Furthermore, events that are categorized as guidance of the search are rated positive/negative when they express a positive/negative opinion regarding the technology under investigation.

When all events are allocated to functions, they can be plotted in figures. For every function, one figure shows the pattern over time. By presenting seven pictures, a clear picture is drawn of the total functional pattern of the innovation system under investigation over time. This gives a quick and strong visible presentation of which functions perform well and which do not, and which periods show good system functioning and which periods do not. In [40] this method is demonstrated for analyzing the development of biomass digestion in the Netherlands.

The final outcome of the process analysis is a storyline, underpinned by several pictures where the events are plotted over time, of how the development of the innovation system has changed over time and the role of the different functions in this development. The story should focus on extracting general patterns like the motors presented in Fig. 2. Cross case analysis can then be used to test whether these patterns are case specific or whether they hold more generally. Insights in these patterns are the first step towards policy recommendations regarding the governance of technology specific innovation systems.

\section{Functions as functionalist explanations?}

The use of functions in social theories has a long and troubled history and, therefore, we choose to end this paper by addressing some salient issues related to so-called functionalism. In general, functionalist theoretical perspectives have two major characteristics in common: (i) the idea of the social world as an objective reality which can be studied by applying the traditional method of the natural sciences; and (ii) the use of a model based on an analogy between the individual organism and society. Both elements have raised severe criticisms, which we wholeheartedly share; they warrant some discussion due to our use of the term 'function'.

Ad (i). The positivist view with which functionalism is associated holds that social systems can be studied objectively, or value-free. The social world is regarded as a mechanistic system, which can be understood by discovering its elements and the laws by which they are directed. Since the social system, in this concept, does not essentially differ from the physical system, it should be studied by using the same methods as is done in studying the physical system. Given these associations we stress that our 
project rejects these 'ambitions' and that we fully recognize the contingent and reflexive nature of social reality that prevents such an analysis. Our principal focus on the entrepreneurs and their activities may prove as an example of this.

Ad (ii). Drawing upon the model of the biological sciences, functionalist analysis examines social conduct in terms of how it contributes to the maintenance of an organic whole. It addresses the role of all social conduct in terms of the vitality of this whole. The major implication here is that the actors-or agents-that are collectively responsible for social conduct, are regarded merely as mechanistic elements that, through their individual activities, either intentionally or unintentionally, serve a 'higher goal'. Agents are compared with the organs-or even cells-of a living body; its goal is survival or, if we keep up the analogy, the persistence of the social system. This is where the notion of function comes in. Functions are activities that contribute to the survival of the social system as a whole, just as the different organs of the human body perform a variety of functions that are necessary for its survival.

In the traditional functionalist perspective, society is then seen as a nested set of 'systems within systems'. A person's psychological system is coupled to a small group-system and this group is enveloped by and connected with a community system; the community system is embedded within society. Talcott Parsons, a key figure in functionalist theorizing, even viewed the whole world as a system of societies $[57,58]$. Functionalists tend to focus mainly on the macro level; which is not that surprising since all individual action is to be explained in terms of system functioning. A serious drawback then is, of course, that delineation would be analytically impossible. After all, in this view reality can only be understood by looking at the totality of things; a true Hegelian perspective.

While such encompassing perspectives are truly tempting, we would like to stress the position of Robert Merton, who departs markedly from the macro level approach of Parsons and others. He regards theory as the development of middle-range propositions [59]. Thus, instead of constructing grand and abstract theories of society, theorists are advised to explain a restricted set of social phenomena. These modest explanations are then to be verified through empirical research and subsequently systematized into theoretical systems of broader scope and content.

Notwithstanding its cumbersome history, we think that the notion of 'function' is useful, provided we stress its heuristic value instead of its positivistic value: it helps to identify, understand, and compare the crucial activities in technology specific innovation systems and it creates insight in the dynamics and possible patterns of technological change and related innovation processes. By doing so, it offers policy makers and other actors involved in innovation processes important insights that may guide and support their actions.

\section{Conclusions}

In this article we presented a framework to study technological change. We explained that the concept of innovation systems is a very useful heuristic framework. However, it suffers from two major flaws. First, it is too static. Second, it lacks sufficient attention for the micro level. We proposed a framework to solve this. This framework is called 'functions of innovation systems'. It focuses on the most important processes that need to take place in innovation systems to lead successfully to technology development and diffusion. By mapping these processes (functions) over time, insight in the dynamics of innovation systems is created. Process analysis is proposed as a suitable research method, since the process approach conceptualizes development and change processes as sequences of events. It explains 
outcomes as the result of the order of events. Applying the process approach to map the functioning of several innovation systems over time, allows us to search for patterns in innovation system dynamics related to technological change.

This insight is likely to be highly relevant for policy. When policy initiatives aim to stimulate or influence the direction of technological change, insight in the current functioning of the relevant technology specific innovation systems is a first step in determining the optimal policy strategy. The next step is to develop and deploy policy initiatives to improve innovation system functioning (systemic instruments). This can be done by stimulating weak functions or by removing blocking mechanisms that prohibit good system functioning.

Further development of the functions of innovation systems approach, based on both theoretical and empirical research into the dynamics of innovation systems-processes at macro and micro level, as well as policy research into the implications for policy makers, policy concepts-and instruments, is necessary to improve the rigor and usefulness of this approach.

\section{Acknowledgements}

The authors are grateful to Harro van Lente and two anonymous reviewers for comments on earlier versions of this paper. Anouk Florentinus, Karen Klomp, Floortje van der Hilst, Chris Kleinschmidt, and Arjen de Jong are thanked for contributing to our insights by working on empirical studies and by many discussions. The Dutch Knowledge Network on System Innovations and Transitions (KSI) is acknowledged for their financial contribution.

\section{References}

[1] R. Smits, S. Kuhlmann, The rise of systemic instruments in innovation policy, Int. J. Foresight Innov. Policyy 1 (1/2) (2004) 4-32.

[2] A. Grübler, Technology and Global Change, Cambridge University Press, Cambridge, 1998.

[3] P. Weaver, L. Jansen, G. Grootveld, E. Spiegel, P. van, Sustainable Technology Development, Greenleaf Publishing, Sheffield, UK, 2000.

[4] F. Geels, Technological Transitions as evolutionary reconfiguration processes: a multi level perspective and a case study, Res. Policy 31 (2002) 1257-1274.

[5] IHDP-IT, International Human Dimensions Program—-Industrial Transformation, website, http://130.37.129.100/english/ o_o/instituten/IVM/research/ihdp-it/index.html, 2005.

[6] A.D. Sagar, J.P. Holdren, Assessing the global energy innovation system: some key issues, Energy Policy 30 (6) (2002) $465-469$.

[7] B.-A. Lundvall, National Systems of Innovation: Towards a Theory of Innovation and Interactive Learning, Pinter, London, 1992.

[8] R. Nelson, S.G. Winter, An Evolutionary Theory of Economic Change, Harvard University Press, Cambridge, MA, 1982.

[9] C. Edquist, Innovation Systems and Innovation Policy: the state of the art. in Invited Paper for DRUID's Nelson-Winter Conference. 2001. Aalborg, Denmark.

[10] A.H. van de Ven, D.E. Polley, R. Garud, S. Venkataraman, The Innovation Journey, Oxford University Press, New York/ Oxford, 1999, p. 422.

[11] S. Jacobsson, A. Bergek, Transforming the energy sector: the evolution of technological systems in renewable energy technology, Ind. Corp. Change 13 (5) (2004) 815-849. 
[12] R.R. Nelson, K. Nelson, Technology, institutions and innovation systems, Res. Policy 31 (2002) 265-272.

[13] C. Edquist, B.A. Lundvall, Comparing the Danish and Swedish systems of innovation, in: R. Nelson (Ed.), National Innovation Systems, Oxford University Press, New York, 1993.

[14] C. Freeman, Technology Policy and Economic Performance: Lessons from Japan, Pinter Publishers Ltd, London, 1987.

[15] R. Kemp, Technology and the transition to environmental sustainability - the problem of technological regime shifts, Futures 26 (10) (1994) 1023-1046.

[16] F.W. Geels, Technological transitions as evolutionary reconfiguration processes: a multi-level perspective and a case-study, Res. Policy 31 (8-9) (2002) 1257-1274.

[17] B. Carlsson, R. Stankiewicz, On the nature, function and composition of technological systems, J. Evol. Econ. 1 (2) (1991) $93-118$.

[18] B. Carlsson, S. Jacobsson, M. Holmen, A. Rickne, Innovation systems: analytical and methodological issues, Res. Policy 31 (2) (2002) 233-245.

[19] D. Archibugi, B.-Å. Lundvall (Eds.), The Globalizing Learning Economy, Oxford University Press, 2001.

[20] T. Hughes, The evolution of large technological systems, in: W. Bijker, T. Hughes, T. Pinch (Eds.), The Social Construction of Technological Systems. New Directions in teh Sociology and History of Technology, MIT Press, Cambridge, MA, 1987.

[21] S. Jacobsson, B.A. Andersson, L. Bangers, Transforming the Energy System, the Evolution of the German Technological System for Solar Cells, 2004.

[22] B.A. Andersson, S. Jacobsson, Monitoring and assessing technology choice: the case of solar cells, Energy Policy 28 (14) (2000) $1037-1049$.

[23] A. Johnson, Functions in Innovation System Approaches. in Paper for DRUID's Nelson-Winter Conference. 2001. Aalborg, Denmark.

[24] R. Galli, M. Teubal, Paradigmatic shifts in national innovation systems, in: C. Edquist (Ed.), Systems of Innovation, Pinter, London, 1997.

[25] C. Edquist, B. Johnson, Institutions and organisations in systems of innovation, in: C. Edquist (Ed.), Systems of Innovation-Technologies, Institutions and Organizations, Pinter, London, 1997.

[26] M. McKelvey, Using evolutionary theory to define systems of innovation, in: C. Edquist (Ed.), Systems of Innovation, Pinter, London, 1997.

[27] X. Liu, S. White, Comparing innovation systems: a framework and application to China's transitional context, Res. Policy 30 (2001) 1091-1114.

[28] S. Jacobsson, B.A. Sanden, L. Bangens, Transforming the energy system-The evolution of the German technological system for solar cells, Technol. Anal. Strateg. Manag. 16 (1) (2004) 3-30.

[29] B.A. Lundvall, B. Johnson, E.S. Andersen, B. Dalum, National systems of production, innovation and competence building, Res. Policy 31 (2) (2002) 213-231.

[30] A. Bergek, Shaping and Exploiting Technological Opportunities: The Case of Renewable Energy Technology in Sweden, in Department of Industrial Dynamics. 2002, Chalmers University of Technology: Göteborg, Sweden.

[31] J.M. Utterback, in: H.B.S. Press (Ed.), Mastering the Dynamics of Innovation, 1994, Harvard.

[32] M.L. Tushman, J.P. Murmann, Dominant designs, technology cycles, and organizational outcomes, Research in Organizational Behavior, vol. 20, 1998, pp. 231-266.

[33] S. Jacobsson, A. Johnson, The diffusion of renewable energy technology: an analytical framework and key issues for research, Energy Policy 28 (9) (2000) 625-640.

[34] N. Rosenberg, Inside the Black Box. Technology and Economics, University Press, Cambridge, 1982.

[35] S. Kuhlmann, P. Boekholt, L. Georghiou, K. Guy, J. Heraud, P. Laredo, T. Lemola, D. Loveridge, T. Luukkonen, W. Polt, A. Rip, L. Sanz-Menendez, R. Smits, Enhancing distributed intelligence in complex innovation systems. Report published within the framework of the Targeted Socio-Economic Research Programme of the European Commission. 1999, ISI-FhG: Karlsruhe.

[36] N. Oudshoorn, T. Pinch (Eds.), How Users Matter. The Co-construction of Users and Technologies, MIT Press, Cambridge, 2004.

[37] G. Tassey, Standardization in technology based markets, Res. Policy 27 (2000) 273-284.

[38] K.a.S.A. Cuhls, Special issue on foresight, J. Forecast 22 (2/3) (2003).

[39] P. Boekholt, M. Lankhuizen, E. Arnold, J. Clark, J. Kuusisto, B. de Laat, P. Simmonds, S. Cozzens, G. Kingsley, R. Johnston, An International Review of Methods to Measure Relative Effectiveness of Technology Policy Instruments, Technopolis, Brighton/Amsterdam, 2001. 
[40] S. Negro, M.P. Hekkert, R.E.H.M. Smits, Explaining the failure of the Dutch innovation system for biomass digestionã a functional analysis, Energy Policy (2006) in press.

[41] R. Suurs, M.P. Hekkert, Naar een Methode voor het Evalueren van Transitietrajecten, Functies van Innovatiesystemen toegepast op 'Biobrandstoffen in Nederland. 2005, Utrecht University, department of Innovation Studies: Utrecht.

[42] I.S.M. Meijer, M.P. Hekkert, J. Faber, R.E.H.M. Smits, Perceived uncertainties regarding socio-technological transformations: towards a framework, Int. J. Foresight Innov. Policy 2 (2) (2006) 214-240.

[43] A.H. Van de Ven, The development of an infrastructure for entrepreneurship, J. Bus. Venturing 8 (1993) 212-230.

[44] W.I. Zangwil, P.B. Kantor, The learning curve: a new perspective, Int. Trans. Oper. Res. 7 (6) (2000) 595-607.

[45] K. Frenken, M. Hekkert, P. Godfroij, R\&D portfolios in environmentally friendly automotive propulsion: Variety, competition and policy implications, Technol. Forecast. Soc. Change 71 (5) (2004) 485-507.

[46] Lente, H.v., Promising Technology, The Dynamics of Expectations in Technological Development, A. Rip, Editor. 1993, Universiteit Twente. p. 260.

[47] H.v. Lente, A. Rip, The rise of membrane technology: from rhetorics to social reality, Soc. Stud. Sci. 28 (2) (1998) $221-254$.

[48] N. Rosenberg, Factors affecting the diffusion of technology, in: N. Rosenberg (Ed.), Perspectives on Technology, Cambridge University Press, Cambridge, 1976.

[49] J. Schot, R.E. Hoogma, Boelie, strategies for shifting technological systems, Futures 26 (1994) 1060-1076.

[50] P.A. Sabatier, An advocacy coalition framework of policy change and the role of policy-oriented learning therein, Policy Sci. 21 (2-3) (1988) 129-168.

[51] k. Klomp, Who believes in biodiesel? A study on coalitions and their influences on the biodiesel network of the Netherlands, Germany and Austria, in Department of Innovation Studies. 2004, Utrecht Univeristy: Utrecht.

[52] A. de Jong, The Evolution of Cogeneration in the Netherlands and Sweden. A Comparison between the Functioning of Two Systems of Innovation, in Department of Innovation Studies, Utrecht University, Utrecht, 2004.

[53] S. Negro, R. Suurs, M.P. Hekkert, A Techno-Institutional Analysis of Energy Systems in Transition, The Dutch Case of Biomass Gasification, in 11th Annual International Sustainable Development Research Conference, 2005, Helsinki.

[54] M.S. Poole, A.H. Van de Ven, K. Dooley, M.E. Holmes, Organizational Change and Innovation Processes, Theories and Methods for Research, Oxford University Press, 2000, p. 406.

[55] A. Abbot, Some comments on "sequence analysis and optimal matching methods in sociology: review and prospect"reply to Levine and Wu, Sociol. Methods Res. 29 (1) (2000) 65-76.

[56] A. Abbot, Sequence analysis: new methods for old ideas, Annu. Rev. Sociology 21 (1995) 93-113.

[57] T. Parsons, The Social System, Routledge \& Kegan Paul Ltd, London, 1951.

[58] T. Parsons, The System of Modern Societies, Prentice Hall, Englewood Cliffs, NJ, 1971.

[59] R. Merton, Social Theory and Social Structure, Free Press, New York, 1968.

Marko P. Hekkert is an Associate Professor of Sustainable Innovation, Roald Suurs and Simona Negro are PhD students, Ruud Smits is a Professor of Technology and Innovation, chair of the Innovation Studies group, and Stefan Kuhlmann is a Professor of Innovation Policy. Stefan Kuhlmann is also a Director of the Fraunhofer Institute for Systems and Innovation Research, Karlsruhe, Germany. All of the above are affiliated with the Copernicus Institute for Sustainable Development and Innovation, Utrecht University in The Netherlands. 